\title{
Rates and predictors of school pregnancy among black women in the North West province, South Africa
}

\author{
Mhele Karabo ${ }^{1}$ and Natal Ayiga ${ }^{2 \$}$ \\ ${ }^{1}$ Population Research and Training Unit, North-West University, Mafikeng Campus, \\ Private Bag X2046, Mmabatho, 2735, South Africa. Email: karabo.mhele@nwu.ac.za \\ ${ }^{2}$ Population Research and Training Unit, North-West University, Mafikeng Campus, \\ Private Bag X2046, Mmabatho, 2735, South Africa. Email: Natal.Ayiga@nwu.ac.za; \\ nayiga1962@gmail.com
}

\begin{abstract}
Learner pregnancy is one of the challenges impeding the unlocking of the potentials of women in sub-Saharan Africa. This paper estimated the prevalence of learner pregnancy and identified its predictors in the North West province of South Africa. The paper used cross-sectional data on 582 black women and the nested logistic regression model to analyse the data. The study found that $38 \%$ of the women become pregnant at school. Learner pregnancy was significantly higher for women who had sexual debut at $<18$ years; were in grades 8 and 9 or higher at age 14; attained <grade 8; had previously dropout of school; had mothers who attained <grade 8; and lived in rural neighbourhoods. We conclude that the prevalence of learner pregnancy is high in the North West province of South Africa, and an integrated approach involving individual, school, family and neighbourhood level strategies are needed to address the problem.
\end{abstract}

Keywords: Education; girl child; MDGs; pregnancy; South Africa

\section{Résumé}

Apprenant la grossesse est un des défis qui empêchent le déverrouillage des potentiels des femmes en Afrique subsaharienne. Cet article a estimé la prévalence de la grossesse de l'apprenant et identifié ses facteurs prédictifs dans la province Nord-Ouest de l'Afrique du Sud. Le papier utilisé des données transversales sur 582 femmes noires et le modèle de régression logistique imbriquées pour analyser les données. L'étude a révélé que $38 \%$ des femmes deviennent enceintes à l'école. Grossesse de l'apprenant est significativement plus élevée pour les femmes qui ont eu des débuts sexuels à $<18$ ans; étaient dans les grades 8 et 9 ou supérieurs à l'âge de 14 ; atteint $<8 \mathrm{e}$ année; auparavant d'abandon de l'école; avait des mères qui atteint $<8 \mathrm{e}$ année; et vivaient dans des quartiers ruraux. Nous concluons que la prévalence de la grossesse de l'apprenant est élevée dans la province du Nord-Ouest de l'Afrique du Sud et un individu impliquant de l'approche intégrée, les stratégies de niveau scolaire, la famille et de voisinage sont nécessaires pour régler le problème.

Mots-clés : Éducation ; fillette ; OMD ; grossesse ; l'Afrique du Sud

\footnotetext{
\$Corresponding Author
} 


\section{Introduction}

Learner pregnancy constitutes a large proportion of teenage unwanted pregnancy in sub-Saharan Africa (Lesetedi et al. 1988), and it is a threat to achieving MDG 2 for girls in this region. It is also a matter of concern because of its association with most social and reproductive health problems faced by young mothers including failure to eradicate extreme poverty and hunger; achieving gender equality and empowerment of women; reducing childhood mortality; improving maternal health; and reversing the spread of HIV/AIDS and its impacts (United Nations, 20I2).

Learner pregnancy is the main cause of school dropout and low educational outcomes for women (Karabo \& Ayiga, 20I3; Perper et al., 2010). It leads to poverty, defined as a lack of income, powerlessness, deprivation, constrained choices, unfulfilled capabilities and a lack of skills (UNDP, 2002), which impedes the expansion of opportunity by locking the potential of young women in the short term. In the long term, learner pregnancy can lead to intergenerational poverty and vulnerability both of which are processes by which poor parents transmit poverty and other forms of vulnerability including sexual risks to their children through a low level human capital trap (Mayer-Foulkes, 2009). Additionally, learner pregnancy exacerbates gender inequality and disempowerment because of the low education and low "capabilities" thereof of girls who were previously pregnant and dropped out of school (Sen, 1999). Low education has also been associated with high childhood and maternal mortality (Aderibigbe et al., 20II) and greater exposure to the risk of HIV/AIDS infection (Mbirimtengerenji, 2007) in sub-Saharan Africa.

\section{Literature Review}

Learner pregnancy is pervasive in sub-Saharan African countries. Previous studies identified individual, school, household and community level factors including young age at sexual debut (Macleod \& Tracey, 2010); a higher age at school entry and lower grade at an older age (Lloyd, 2005); grade repetition and school withdrawals as predictors of learner pregnancy (Marteleto et al., 2008). Other predictors are sexual exploitation by fellow male students and teachers (Boerma et al, 1998); sexual violence by a close partner and or peers (Pallitto \& Murilo, 2008); family structures characterized by broken, single parent, extended families and large numbers of siblings (Hillis et al., 2010; Rwenge, 2003); household poverty (Adeboyejo \& Onyeonoru, 2003); and a lack of discourse between parents and children on sexual matters (Izugbara, 2008). Neighbourhoods as a spatial construct have also contributed to learner pregnancy (Burgard \& Lee-Rife, 2009).

South Africa, with $30 \%$, has one of the highest learner pregnancy prevalence rates in sub-Saharan Africa (National Research Council \& Institute of Medicine, 2005). In addition to some of the factors outlined above, learner pregnancy in South Africa is attributed to society's tolerant attitude towards early age at sexual debut and premarital childbearing (Pillaw, 2006); and the rapidly changing family structure (Hilliset al., 2010). The impacts of learner pregnancy in South Africa include the high school dropout rate (Shisana et al., 20l0) and low school re-entry rates for the girl child (Ayiga \& Karabo, 20I4); and poverty faced by teenage mothers and their children (Wright \& Noble, 2012). This has created the need to expand the children's social protection programme (Department of Social Development [South Africa] et al., 2012). The challenges now being faced by South Africa including high youth unemployment, aging, demand for quality education, health services, housing and budgetary constraints suggest that it may not be possible to sustain the social protection programme without plugging the supply of socially vulnerable children (Pauw \& Mncube, 2007).

Although the level of learner pregnancy in the North West province reduced slightly from 2, 197 to 2,157 over the 2007 and 2008 period (Department of Basic Education [South Africa], 2010), it has remained high and the factors driving the high prevalence of learner pregnancy in the province remain poorly understood. Unlike other provinces in South Africa, no population based studies to identify the factors predicting learner pregnancy have been conducted in the North West province. This has called for a study to investigate, inform and strengthen provincial and local level interventions to reduce learner pregnancy and its impacts on teenage women. This paper therefore estimated the prevalence and identified the predictors of learner pregnancy in North West province of South Africa. 


\section{Data and methods}

\section{Study population}

The paper used data on 582 black women collected by use of cross-sectional research design from two districts (Bojanala and Modiri-Molema) in the North West Province of South Africa in 2010. The event history method was used to collect retrospective data on events that occurred to women and the time at which they occurred from age 14 when the women were enrolled in school to the date of permanent school dropout or school re-entry and matriculation.

A multi-stage sampling design was used to select women for interview. The first stage involved selecting the districts of Bojanala and ModiriMolema out of the four districts of North West province by use of simple random sampling. In the second stage four local municipalities were selected by use of stratified random sampling using the urban and rural neighbourhoods as a stratification criterion. In the third stage, 600 households were selected through systematic sampling. From each household, one woman aged 22 years or older was selected for interview. The eligibility criteria used in selecting the target women were being black, enrolled in school at age 14 and not having experienced a pregnancy before age 14 .

A structured and pre-coded questionnaire was used to collect individual, school, household and neighbourhood level variables and pregnancy experience of 600 women who were enrolled in school at age 14 and had no previous pregnancy experience. The data were collected through face to face interviews by trained research assistants. The questionnaire was first translated into Setswana, the dominant language in the North West province and then back to English to ensure that the meanings of the translations remained consistent. However, 18 questionnaires were dropped from this analysis because of incomplete data.

\section{Ethical issues}

Ethical approval was obtained from the Higher Degrees and Research Committee of the Faculty of Human and Social Sciences of North-West University, Mafikeng Campus. Permission to collect data was also obtained from the North West Premier's office, area chiefs and district managers. Informed consent was obtained from each respondent after assurance that their identity and data collected would remain confidential. Respondents were also informed of their right to participate or withdraw from the study at any stage without consequences.

\section{Measures}

The dependent variable was becoming pregnant while enrolled in school from age 14. If learner pregnancy occurred any time from age 14, the pregnancy status of the woman was coded "I" and "0" if otherwise.

The independent covariates included individual, school, household and neighbourhood level data. The individual level covariates were age cohorts which was categorized as less than 25, 25-29 and 30 years or older because we expect age at sexual debut to vary by age cohorts. Birth order was recorded as $1^{\text {st }}, 2^{\text {nd }}, 3^{\text {rd }}$ and $4^{\text {th }}$ or higher; and age at sexual debut was recorded as less than 18 and 18 years or older. The school level covariates included age at school entry which was recorded as less than grade 7, grade 7 and grade 8 or higher; grade at age 14 was recorded as less than grade 8 , grade 8 and grade 9 or higher; and the highest grade the women attained was recorded as less than grade 8 , grades 8- IO and grade II or higher. Additionally, previous school dropout status was also included and recoded as never dropped out and dropped out of school.

Regarding household level covariates, the number of siblings recorded as "I", " 2 ", " 3 " and " 4 " or higher; family structure recorded as both parent, single parent mother headed, single parent father headed and extended families; and the highest grade attained by the mothers' of the women which was recorded as less than grade 8 , grades $8-10$ and grade II or higher were analysed. Neighbourhood level covariates analysed were perceived schooling status of neighbourhood peers which was categorized as not in school and in school; and district and place of residence were Bojanala and Modiri-Molema and rural and urban neighbourhoods respectively.

\section{Statistical analysis}

Data analysis was done by use of SPSS (PASW version 2I) at three levels. The first, univariate analysis, described the individual, school, household and neighbourhood level profiles of the women from age 14 until they either permanently dropped out of school or matriculated at grade 12 . The result of the univariate analysis is presented in frequency distributions. The bivariate analysis examined differentials and the association between learner pregnancy and women's individual, school, household and neighbourhood level covariates by 
use of the Pearson's chi-square statistic. The levels of associations were tested at the $95 \%$ confidence interval $(p<0.05)$.

At the multivariate level, the nested binary logistic regression model (Elisa \& Wang, 1992) was used to test the hypothesis that "age at sexual debut is a significant predictor of school pregnancy after controlling the effects of other individual, school, household and neighbourhood level covariates simultaneously". It was also used to identify other significant predictors of learner pregnancy. This method of analysis was chosen because the dependant variable is dichotomous and was coded "I" if a woman became pregnant at school at any time from age 14 and " 0 " if otherwise. The dependent variable therefore satisfied the criteria for the use of the model. The covariates used to fit the multivariate models were those that were significantly associated with learner pregnancy status at the bivariate level of analysis.

\section{Results}

\section{Profile of the sample}

Table I presents the profiles of the study sample. The table shows that the mean age of the women was 28 years and $43.6 \%$ of the women were 30 years or older; nearly $30.8 \%$ were $25-29$ years; and nearly $25.6 \%$ were under 25 years. The mean birth order was 2.7 and $32.1 \%$ were of birth order "I", $21.6 \%$ were of birth order " 2 " and $30.1 \%$ were of birth "4" or higher. Only $16.2 \%$ of the women were of birth order " 3 ". The mean age at sexual debut was 18 years and nearly 6 in 10 of the women had sexual debut at 18 years or older; and nearly 4 out 10 of the women (38\%) became pregnant at school.
Distribution by school level characteristics shows that the mean age of the women at school entry was 7 years. About 38\% of the women entered schooling for the first time at less than 7 years, $49 \%$ entered schooling at 7 years and only $14.4 \%$ entered schooling at 8 years or older. The mean grade at age 14 was grade 8 and $45.7 \%$ of the women were in less than grade 8 at age 14, nearly $33.8 \%$ were in grade 8 at age 14 and only one fifth were in grade 9 or higher at age 14. Table I also presents the highest grade attained by the women showing that the mean grade they attained was grade II. The highest grade attained by more than half of the women was grade II or higher followed by grades $8-10(25 \%)$, and just over $20 \%$ attained less than grade 8 . About $47 \%$ of the women previously dropped out of school and the mean grade at school dropout was grade 9.

Furthermore, Table I presents the women by household level characteristics. The table shows that the mean sibling number of the women was 3.4 and the majority (43\%) had " 4 " or more siblings. Forty one percent of the women lived in both parent families, $37 \%$ lived in single parent mother headed family, nearly $12 \%$ lived in single parent father headed family and only I $\%$ lived in extended family. The mean grade attained by the mothers' of the women was grade 7.4 , the majority $(46.4 \%)$ attained grades $8-10$ and only $18.4 \%$ of the mothers of the women attained grades 11 or higher. Regarding neighbourhood characteristics, 6 in 10 of the women perceived that their neighbourhood peers were not in school; nearly 7 in 10 and $35 \%$ of the women were from Bojanala and Modiri-Molema districts respectively; and nearly 8 in 10 and $22 \%$ of the women were living in urban and rural neighbourhoods respectively.

\section{Table I Percentage distribution of women by selected characteristics}

\begin{tabular}{lcc}
\hline Characteristics & $\%$ & Number of women \\
\hline Age cohort & & 149 \\
$<25$ & 25.6 & 179 \\
$25-29$ & 30.8 & 254 \\
$35+$ & 43.6 & 582 \\
Median age of women & 28 & \\
Birth order & & 187 \\
1 & 32.1 & 126 \\
2 & 21.6 & 94 \\
3 & 16.2 & 175 \\
4 or higher & 30.1 &
\end{tabular}


Vol. 28, No. I: Suppl on Population Issues in South Africa, May, 2014

Mean birth order

Age at first sex

40.5

$<18$ years

59.5

18 years or older

Median age at first sex

Ever been pregnant at school?

Yes

No

Age at school entry

$<7$

7

47.8

8 years or older

Median age at school entry

Grade at age 14

$<8$

8

9 or higher

Median grade at age 14

Highest grade attained

$<8$

8-10

I I of higher

Mean highest grade attained

Previous school dropout status

Never dropped out

Median grade at previous school dropout

Family structures

Both parents

Single parent mother headed

Single parent father headed

Extended

10.8

Number of siblings

Mean number of siblings

Mothers highest education

$<8$

8- 10

I lor higher

Mean level of education

Number of siblings

Mean number of siblings

Perceived schooling status of neighbourhood peers

Not in school

District of residence 
Place of residence

Urban $\quad 22.5 \quad 131$

Rural $\quad 77.5$

451

Total

100.0

582

\section{Differentials in learner pregnancy}

Table 2 presents differentials in learner pregnancy by selected covariates. The table shows that learner pregnancy increased with age cohorts from $31 \%$ in the under 25 year age cohort to $45.3 \%$ in the 30 years or older age cohorts. Learner pregnancy decreased with increase in age at sexual debut. Nearly $58 \%$ and $25.4 \%$ of the women who had the first sex at less than 18 and 18 years or older respectively, experienced learner pregnancy. The results show that age cohort and age at sexual debut were significantly associated with learner pregnancy at $\mathrm{p}<0.05$.

Learner pregnancy also increased with increase in age at school entry. Fifty five percent of the women who entered school at 8 years or older became pregnant at school followed by those who entered school at 7 years (4I.4\%) and less than 7 years (29\%). Learner pregnancy decreased with increase in grade at age 14 from $48.1 \%$ at less than grade 8 , to $31.5 \%$ at grade 8 and nearly $29 \%$ at grade 9 or higher. Additionally, learner pregnancy increased from $46.2 \%$ to $59.3 \%$ among women who attained less than grade 8 and grades $8-10$ before declining to $26.1 \%$ among women who attained grade 11 or higher. Regarding the effect of previous school dropout experience, nearly 6 in 10 women who previously dropped out of school became pregnant at school. The results show that age at school entry, grade at age 14, highest grade attained and previous school dropout experience were significantly associated with learner pregnancy at $p<0.05$.

Additionally, Table 2 shows that learner pregnancy was higher among women in single mother headed family $(37.7 \%)$ followed by single father headed family (4I.8\%) and extended (46\%) family than in both parent family (36.1\%). Learner pregnancy was higher among women whose mothers' attained grades $8-10$ (46.4\%) followed by those who attained less than grade $8(35.2 \%)$ and grade II or higher ( $18.4 \%)$. Table 2 also shows that more women who perceived that their neighbourhood peers were in school (46.3\%) became pregnant at school than those who perceived that their neighbourhood peers were not in school (33.7\%); and more women who lived in rural $(44.2 \%)$ than urban (18.3\%) neighbourhoods also became pregnant at school. The results show that the level of education attained by the mothers' of the women, perceived schooling status of neighbourhood peers by the women in this sample and type of neighbourhood residence were significantly associated with learner pregnancy at $\mathrm{p}<0.05$.

Table 2 Percentage distributions of women by learner pregnancy status and selected characteristics

\begin{tabular}{|c|c|c|c|c|}
\hline \multirow[t]{2}{*}{ Characteristics } & \multicolumn{2}{|c|}{$\begin{array}{l}\text { Have you ever been pregnant at } \\
\text { School? }\end{array}$} & \multirow[b]{2}{*}{$\mathbf{X}_{2}$} & \multirow[t]{2}{*}{ Total } \\
\hline & Yes & No & & \\
\hline \multicolumn{5}{|l|}{ Age cohort } \\
\hline$<25$ & $30.9(46)$ & $69.1(103)$ & 9.4 I*** & $100.0(149)$ \\
\hline $25-29$ & $35.2(63)$ & $64.8(446)$ & & $100.0(179)$ \\
\hline $35+$ & $45.3(115)$ & 54.7 (139) & & $100.0(254)$ \\
\hline \multicolumn{5}{|l|}{ Birth order } \\
\hline 1 & $40.1(75)$ & $59.9(112)$ & 3.29 & $100.0(187)$ \\
\hline 2 & $43.7(55)$ & $56.3(7 \mathrm{I})$ & & $100.0(126)$ \\
\hline 3 & $33.0(31)$ & $67.0(63)$ & & $100.0(94)$ \\
\hline $4+$ & $36.0(63)$ & $64.0(112)$ & & $100.0(175)$ \\
\hline \multicolumn{5}{|c|}{ Age at first sex in years } \\
\hline$<18$ & $57.6(136)$ & $42.4(100)$ & $61.42 * * * *$ & $100.0(236)$ \\
\hline $18+$ & $25.4(88)$ & $74.6(258)$ & & $100.0(346)$ \\
\hline
\end{tabular}


Vol. 28, No. I: Suppl on Population Issues in South Africa, May, 2014

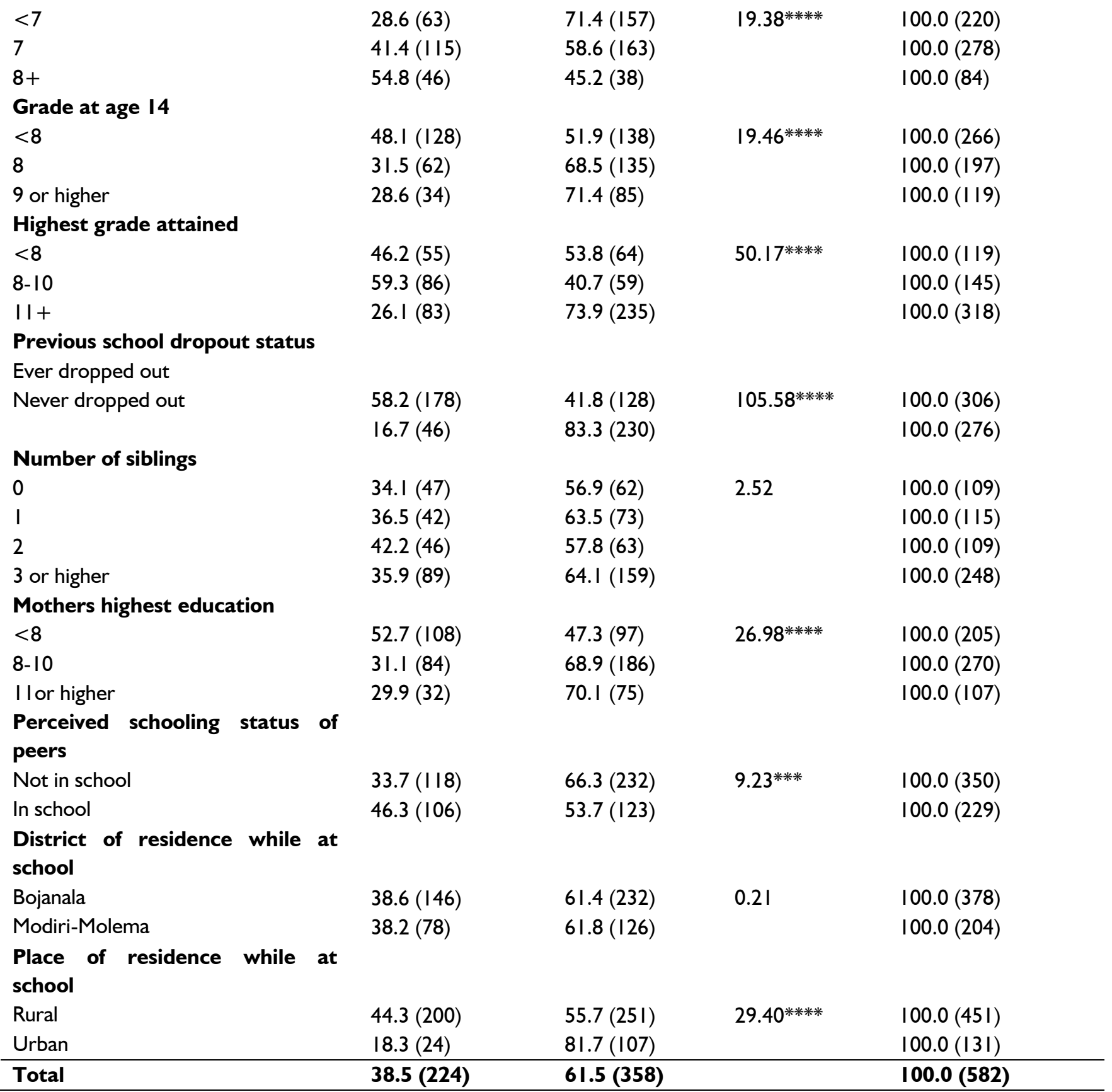

Levels of significance: $*=0.05$; $* *=0.01$; $* * *=0.001$; $* * * *=0.000$ I

\section{Predictors of learner pregnancy}

The adjusted coefficients predicting the effects of individual, school, household and neighbourhood level covariates on learner pregnancy are presented in Models I-III in Table 3. Model I shows that sexual debut at less than 18 years significantly increased learner pregnancy by $4.07 \quad(\mathrm{p}<0.000 \mathrm{I})$ times. Women who were in the under 25 and 25-29 years age cohorts were $50 \% \quad(p<0.00 \mathrm{I})$ and $36 \%$ $(p<0.01)$ respectively less likely to have experienced learner pregnancy after adjustments. Model II shows that after adjusting for the effects of school level covariates, initiating sexual debut at less than 18 years significantly increased learner pregnancy by $3.62(\mathrm{p}<0.000 \mathrm{I})$ times. Women who were in less than grade 8 at age 14 and previously dropped out of school were I.50 $(p<0.0 \mathrm{I})$ and nearly 4.0 $(p<0.000 \mathrm{I})$ times significantly more likely to have experienced learner pregnancy. Conversely, women who attained less than grade 8 and grades 8 10 were $88 \%(p<0.000 I)$ and $79 \%(p<0.00 I)$ significantly less likely to have experienced learner pregnancy. Model II also shows that learner pregnancy significantly increased by $2.62(\mathrm{p}<0.000 \mathrm{I})$ and $2.73(p<0.000 I)$ times among women whose mothers' highest grade attainment was less than grade 8 and grades 8-10 respectively. Model III presents results on effects of age at sexual debut on 
learner pregnancy after controlling the effects of selected school, household and neighbourhood covariates simultaneously. The model shows that although the effect of initiating sexual debut at less than 18 years reduced in Models II and III, it remained a significant predictor of learner pregnancy, and women who had sexual debut at less than 18 years were $3.00(p<0.000 \mathrm{I})$ times more likely to have experience learner pregnancy than women who had sexual debut at 18 years or older.

Model III also shows that women who were in grade 8 and grade 9 or higher at age 14 and attained less than grade 8 were $1.33(p<0.01), \quad 1.64$ $(p<0.05)$ and $\mathrm{I} .4 \mathrm{I}(\mathrm{p}<0.000 \mathrm{I})$ times respectively significantly more likely to have experienced learner pregnancy. Additionally, women who previously dropped out of school, whose mothers' highest educational attainment was less than grade 8 and lived in rural neighbourhoods were $4.5(\mathrm{p}<0.00 \mathrm{I})$, $1.56(p<0.05)$ and $3.18 \quad(p<0.000 \mathrm{I})$ times respectively significantly more likely to have experienced learner pregnancy. Conversely, women whose highest grade attainment was grades 8-10 and those who perceived that their neighbourhood peers were in school were $78 \%$ $(p<0.0 \mathrm{I})$ and $46 \% \quad(\mathrm{p}<0.0 \mathrm{I}) \quad$ respectively significantly less likely to have experienced learner pregnancy. From Model III, it can be concluded that a lower age at sexual debut ( $<18$ years), a higher grade at age 14 (grade 8 and grade 9 or higher), a low school grade attainment by both the women and their mothers, previous school dropout experience and living in rural neighbourhoods remained significant predictors of learner pregnancy in this study population.

Table 3 Logistic regression coefficients showing the adjusted effects of selected individual, school, household and neighbourhood level covariates on learner pregnancy

\begin{tabular}{|c|c|c|c|c|c|c|}
\hline \multirow[t]{2}{*}{ Selected covariates } & \multicolumn{2}{|l|}{ Model I } & \multicolumn{2}{|c|}{ Model II } & \multicolumn{2}{|c|}{ Model III } \\
\hline & OR & $\mathbf{C l}$ & OR & $\mathbf{C l}$ & OR & $\mathbf{C l}$ \\
\hline \multicolumn{7}{|l|}{ Age cohort } \\
\hline Under 25 & $0.50 * * *$ & $0.31-0.79$ & 0.74 & $0.44-1.23$ & 0.80 & $0.47-1.34$ \\
\hline $25-29$ & $0.64 *$ & $0.42-0.98$ & 0.90 & $0.56-1.44$ & 0.95 & $0.59-1.55$ \\
\hline $30+\AA$ & 1.00 & & 1.00 & & 1.00 & \\
\hline \multicolumn{7}{|l|}{ Age at first sex } \\
\hline$<18$ & 1.00 & & 1.00 & & 1.00 & \\
\hline 18 ® & $4.07 * * * * *$ & $0.17-0.35$ & $3.62 * * *$ & $* 0.22-0.44$ & $3.00 * * *$ & $* 0.21-0.46$ \\
\hline \multicolumn{7}{|l|}{ Age at school entry } \\
\hline$<7 \AA$ & & & 1.00 & & 1.00 & \\
\hline 7 & & & 0.67 & $0.34-1.14$ & 0.76 & $0.39-1.46$ \\
\hline 8 years or older & & & 0.84 & $0.46-1.43$ & 0.95 & $0.52-1.73$ \\
\hline \multicolumn{7}{|l|}{ Grade at age 14} \\
\hline$<8$ & & & $1.50 * *$ & $0.88-2.57$ & $1.33 * *$ & $0.74-2.42$ \\
\hline 8 & & & 1.15 & $0.65-2.03$ & $1.64 *$ & $0.88-1.75$ \\
\hline 9 or higher ${ }^{\circledR}$ & & & 1.00 & & 1.00 & \\
\hline \multicolumn{7}{|c|}{ Highest grade attained } \\
\hline$<8$ & & & $0.12 * * *$ & $* 0.04-0.32$ & $1.41 * *=$ & $* 0.05-0.40$ \\
\hline $8-10$ & & & $0.21^{* * * *}$ & $0.08-0.57$ & $0.22 * *$ & $0.07-0.63$ \\
\hline I I or higher ${ }^{\circledR}$ & & & 1.00 & & 1.00 & \\
\hline \multicolumn{7}{|c|}{ Previous school dropped } \\
\hline Ever dropped out ${ }^{\circledR}$ & & & 1.00 & & 1.00 & \\
\hline Never dropped out & & & $3.97 * * *$ & $* 1.42-8.02$ & $4.50 * * *$ & $* 3.24-10.1$ \\
\hline $\begin{array}{ll}\begin{array}{l}\text { Mothers' level } \\
\text { education }\end{array} & \end{array}$ & & & & & & \\
\hline$<=7$ & & & $2.73 * * *$ & $*|.68-4.4|$ & $1.56 * *$ & $0.89-1.23$ \\
\hline $8-10$ & & & $1.93 * * *$ & $1.24-3.01$ & 0.87 & $01.21-2.45$ \\
\hline I I or higher $\mathbb{R}$ & & & 1.00 & & 1.00 & \\
\hline
\end{tabular}


Both parents ${ }^{\circledR}$

Single mother headed

Single father headed

0.69

0.39

Foster/extended

Perceived schooling

status

of neighbour peers

In school

Not in school ${ }^{\circledR}$

Place of residence at 14

Urban ${ }^{\circledR}$

Rural
$0.54 * * * * 0.35-0.82$

1.00

Constant

$1.86^{* * * *}$

$2.45^{* * * *}$

3.18**** $\quad 1.80-5.59$

( ${ }^{2}$ Reference category; $\mathrm{OR}=$ odds Ratio; $\mathrm{Cl}=$ Confidence interval; levels of significance: ${ }^{*}=0.05$; $* *=0.01$; $* * *=0.00 \mathrm{I} ; * * * *=0.000 \mathrm{I}$

\section{Discussion}

Learner pregnancy, as a component of teenage pregnancy, is one of the challenges that have prevented the unlocking of the potentials of a large proportion of women in sub-Saharan Africa (UNDP, 2002), and contributed greatly in perpetuating poverty and poor reproductive health in this region (Mmbaga et al., 2012). Previous studies have also argued that this phenomenon contributes significantly to the failure of many countries in this region towards attaining the MDGs (United Nations, 2012). South Africa is one of the countries in subSaharan Africa where school pregnancy is common (Willan, 20I3). It has contributed to the high school dropout rates, leading to the poor educational outcomes among black women. This study, therefore, estimated the prevalence of learner pregnancy and identified some of the most significant predictors of learner pregnancy among black women who were enrolled in school at age 14 and had no previous pregnancy experience.

The study found that $38 \%$ of the women in the sample experienced learner pregnancy. At the bivariate level, learner pregnancy increased with age cohorts and low age at sexual debut; higher age at school entry, lower grades at age 14, lower grade attainment and among women who previously dropped out of school. Additionally, learner pregnancy was higher for women whose mothers had a low school grade attainment and those who perceived that their neighbourhood peers were in school. Learner pregnancy was also prevalent for women in rural neighbourhoods. At the multivariate level, the odds of becoming pregnant at school were higher for women who had sexual debut at less than
18 years; were in grades 8 and 9 or higher at age 14 , had attained less than grade 8 and previously dropped out of school; had mothers' who attained less than grade 8 education; and lived in rural neighbourhoods.

Young age at sexual debut and the high prevalence of premarital sex has increased the susceptibility of teenagers to learner pregnancy. The early age at sexual debut has been attributed to the erosion of cultural and sexual values and norms, which has somehow allowed young people to express sexual behaviours which were previously disapproved, freely (Bello \& Adesemoye, 2012). A previous study attributed the young age at sexual debut in South Africa to the apparent tolerance of premarital sex (Pillow, 2004). The rapidly changing family structure, that is now characterized by single parent households, extended and child headed families, encourages early age at sexual debut as a survival strategy against the stresses of poverty, subsequently leading to pregnancy (Oleke, et al., 2006).

Additionally, some studies have suggested that lack of paternal and maternal support (Karabo \& Ayiga, 2013; Ellis et al., 2003); lack of child-parent discourse on sexual matters, which is the case in most sub-Saharan Africa, makes teenage girls to rely more on their peers for support (Mmbaga et al., 20I2). Inappropriate advice and emulating peers to gain acceptance by engaging in sexual activities with older men "the sugar daddy syndrome" increases the susceptibility of teenage women to pregnancy (Resnick, 2007).

A large number of women in this study were older than the recommended grade (grade 8 ) at age 14 , which indicates that they joined school late or 
they repeated grades due to poor performance or previously dropped out or withdrew from schooling. The elevated risk of learner pregnancy for girls who attained less than grade 8 at age 14 and previous dropouts in this study is consistent with the suggestion that older age at a lower grade or slow grade progression due to grade repetition and withdrawal from schooling are risk factors for learner pregnancy for girls (UNESCO, 20II). Grade repetition poses a significant problem for girls because as they get older (Grant \& Hallman, 2006), schooling competes with other life events and the older age at a low grade increases their distaste for schooling and also reduces the level of support from parents and guardians to keep them in school (Kane, 2004). Additionally, older age at school competes with other roles, usually of an adult nature, which effectively shifts the girls' interest to non-school activities such as remunerative work to support themselves and or their families (Sabates et al., 2010). Other factors that could lead to learner pregnancy for older girls include contraceptive failure and not feeling comfortable obtaining and using contraceptives (Santelli et al., 2006), use of alcohol and other illicit entertainment drugs (Deardorff, 2006), and pressures to have unprotected sex or fear to ask a partner to use condoms (Alio et al., 2009).

The finding that school pregnancy is higher in rural neighbourhoods is consistent with observations by a previous study (Mchnu, 20I2). In this study, we suggest that the higher teenage learner pregnancies could be attributed to the creeping changes in family structures in rural neighbourhoods and its effects on sexual behaviour which has already been discussed. The modernization processes, have increased the diversity of social organizations even in rural areas leading to the reproduction of urban conditions and value systems in rural areas (Hobbs, 1995), which have eroded rural sexual norms, leading to teenage sexual activity and pregnancy. Additionally, the lack of or inadequate sporting and recreational facilities that can engage teenagers and protect them from risky health behaviours including sexual behaviour could explain the high rate of learner pregnancy in rural neighbourhoods (Erulkar et al., 200I).

South Africa's large population of teenage learners provides an opportunity to address teenage pregnancy using school based interventions. The fact that most teenagers enter school before sexual debut is a great opportunity to inculcate norms, values, skills and aspirations that delay sex and pregnancy. The increasing family fragility must also be addressed because parents as primary socialising agents are better positioned to influence the sexual behaviour and outcomes of children through constant support and supervision that encourages sexual discourse. Peers are another important group that is relied upon for guidance and direction, whose influence can be tapped by organizing school and community peer support groups. Additionally, policies that focus on increasing access to and uptake of adolescent reproductive health services and reduction of sexual violence are also recommended. The success of school and community based interventions to reduce teenage pregnancy will curtail the risk of intergenerational transfer of poverty and other forms of vulnerability including teenage learner pregnancy among teenage girls in South Africa.

\section{Limitations}

Although this paper has identified some significant predictors of learner pregnancy, it has some limitations. Firstly, the findings of the study could have been affected by the accuracy of reporting data on pregnancy and childbirth which issues are usually affected by social desirability biases. It is likely that some of the women did not report becoming pregnant at school, which is likely if the pregnancy was aborted. Secondly, some of the events that could have affected learner pregnancy status took place a long time ago and could have been omitted. For example school time socioeconomic status of the women was not analysed, which could have affected the results obtained in this study, particularly the high significant levels of some of the covariates. Thirdly, the use of cross-sectional retrospective data makes the temporality of learner pregnancy and some of the predictors used in this study unknown.

\section{Conclusion}

We conclude that the problem of learner pregnancy is prevalent in the North West province, calling for learner pregnancy to be examined from a broader perspective including individual, school, household and neighbourhood level environments in which teenage learners operate. Key among these issues are the apparent tolerance of early age at sexual debut and premarital childbearing, the slow school progression reflected by older age at a lower school grade and structural factors such as the changing 
family structure and spatial neighbourhood vulnerabilities which could lead to intergenerational transfer of vulnerability including learner pregnancy. This is reflected in the low education attainment of both the women who become pregnant at school and that of their mothers, which suggests that daughters, like their mothers, were not equipped with skills, values, attitudes and aspirations to prevent learner pregnancy.

\section{References}

Adeboyejo, T \& Onyeonoru, I 2003. "Aspects of home environment and adolescent sexual behaviour in South Western Nigeria." African Population Studies 20, (I):45-52.

Aderibigbe, A.A., Araoye, M.O., Akande, T.M., Musa, O.I., Monehin, J.O \& Babatunde, O.A 2011. "Teenage pregnancy and prevalence of abortion among In-school adolescents in North Central Nigeria." Asian Social Sciences 7, (I):122127.

Alio, A.P., Nana, P.N \& Salihu, H.M 2009. "Spousal violence and potentially preventable single and recurrent spontaneous foetal loss in an African setting: cross-sectional study." The Lancet 373:318-324.

Ayiga, N \& Karabo, M 2014. "Predictors of school reintegration of black women who previously dropped out of school in the North West province of South Africa." African Population Studies 28, (I):475-485.

Bello, S.M \& Adesemoye, S 2012. "Western films and teenagers in Nigerian society: The question of cultural promotion." Continental Journal of Arts and Humanities 4, (2): 18-26.

Boerma, T., Schapink, D \& Mgalla, Z 1998. "Protecting school girls against sexual exploitation: A guardian programme in Mwanza, Tanzania." Reproductive Health Matters 6, (I2):19-30.

Burgard, S \& Lee-Rife, S 2009. "Community characteristics, sexual initiation, and condom use among young black South Africans." Journal of Health and Social Behaviour 50:293-309.

Deardorff, J., Gonzales, N.A., Christopher, F.S., Roosa, M.W \& Millsap, M.E 2005. "Early puberty and adolescent pregnancy: The influence of alcohol use." Paediatrics II6, (6): I45 I-I456.

Department of Basic Education 2010. Annual school surveys: Report for ordinary schools 2007 and 2008. Pretoria: Republic of South Africa.
Department of Social Development (DoSD), South African Social Security Agency (SASSA) \& UNICEF 2012. The South African child support grant impact assessment: Evidence from a survey of children, adolescents and their households. Pretoria: UNICEF South Africa.

Ellis, B.J., Bates, J.E., Dodge, K.A., Fergusson, D.M., Horwood, L.J., Pettit, G.S \& Woodward, L 2003. "Does father absence palace daughters at special risk for early sexual activity and teenage pregnancy?" Child Development 74, (3):80I-82I.

Elisa, T.L \& Wang, J 1992. Statistical methods for survival data analyses. 2nd ed. New York, NY: John Willy \& Sons, Inc: 289-314.

Erulkar, A.S., Beksinska, M \& Cebekhulu, Q 2001. An assessment of youth centres in South Africa. Population Council and Reproductive Health Research Unit.

Grant, M \& Hallman, K 2006. Pregnancy-related school dropout and prior school performance in South Africa. New York, USA: Population Council Inc. No. 212.

Hillis, A.D., Anda, R.F., Dube, S.R., Felitti, V.J., Marchbanks, P.A., Macaluso, M \& Marks, J.S 2010. "The protective effect of family strengths in childhood against adolescent pregnancy and its long term psychosocial consequences." The Permanente Journal 14, (3): 18-27.

Hobbs, D 1995. Social organization in the countryside. In E. Castle (ed). The changing American countryside: Rural people and places. Lawrence, KS: University Press of Kansas, pp. 369-396

Izugbara, C 2008. "Home-based sexuality education: Nigerian parents discussing sex with their children." Youth Society 39:575-600.

Kane, E 2004. Girls' Education in Africa: what do we know about strategies that work? Washington DC: World Bank.

Karabo, M \& Ayiga, N 2013. "Factors influencing high dropout rate of girl child from education: $\mathrm{A}$ case study of black women in North West province South Africa." Journal of Social Development in Africa 28, (1): I I I-138.

Lesetedi, L.T., Mompati, G.D., Khulumani, P., Lesetedi, G.N \& Rutenberg, N 1989. Botswana family health survey II, 1988. Gaborone, Botswana: Central Statistics Office and Family Health Division, Ministry of Health, and Columbia, MD: Institute for Resource Development. 
Lloyd, C 2005. Growing up global: The changing transition to adulthood in developing countries. Washington: National academy press.

Macleod, C.I \& Tracey, T 20I0. "A decade later: follow-up review of South African research on the consequences of and contributory factors in teen-aged pregnancy." South African Journal of Psychology 40, (I):|8-3|.

Marteleto, L., Lam, D \& Ranchhod, V 2008. "Sexual behaviour, pregnancy and schooling among young people in urban." Studies in Family planning 39, (4):35I-368.

Mayer-Foulkes, D 2009. Economic geography of human development: Stratified growth in Bolivia, Brazil, Guatemala and Peru, Research for Public Policy, Human Development. HD-06-2009, RBLAC-UNDP, New York.

Mbirimtengerenji, N.D 2007. "Is HIV/AIDS epidemic outcome of poverty in Sub-Saharan Africa?" Croat Medical Journal 48:605-6I7.

Mchunu, G., Peltzer, K., Tutshana, B \& Seutlwadi, L 2012. "Adolescent pregnancy and associated factors in South African youth." African Health Sciences 12, (4):426-434

Mmbaga, E.J., Leonard, F \& Leyna, G.H 2012. "Incidence and predictors of adolescent's early sexual debut after three decades of HIV interventions in Tanzania: A time to debut analysis." PLoS ONE 7, (7): e4I700. doi:10.137I/journal.pone.004I700.

National Research Council \& Institute of Medicine of the National Academies (NRC-IOM) 2005. Growing up global: The changing transitions to adulthood. In C.B. Lloyd (ed). Developing Countries. Washington, DC: The National Academies Press, pp. 53-59.

Oleke, C., Blystad, A., Moland, K.M., Rekdal, O.B \& Heggenhougen, K 2006. "The varying vulnerability of African orphans: The case of Langi, Northern Uganda." Childhood I3, (2):267284.

Pallitto, C.C \& Murillo, V 2008. "Childhood abuse as a risk factor for adolescent pregnancy in $\mathrm{El}$ Salvador." Journal of Adolescent Health 42, (6):580-586.

Pauw, K \& Mncube, L 2007. Expanding the social security net in South Africa: Opportunities, challenges and constraints. Development Policy Research Unit, University of Cape Town, DPRU Working Paper 07/I27: ISBN Number: 978-I920055-5I-6.
Perper, K., Peterson, K \& Manlove, J 20I0. Diploma attachment among teen mothers. child trends. Fact Sheet: Washington, DC.

Pillow, W.S 2004. Unfit subjects: Educational policy and the teen mother. New York: Routledge Falmer.

Resnick, M.D., Blum, R.W., Bauman, K.E, Harris, K.M., Jones, J., Tabor, J. et al 2007. "Protecting adolescents from harm: findings from the national longitudinal study on adolescent health." Journal of American Medical Association 278: 823-832.

Rwenge, M 2003. "Poverty and sexual risk behaviour among young people in Bamenda, Cameroon." African Population Studies 18, (I):91-104.

Sabates, R., Hossain, H \& Lewin, K.M 2010. School dropout in Bangladesh: New insights from longitudinal evidence CREATE pathways to access. Research Monograph No. 49.

Santelli, J.S., Morrow, B., Anderson, J.E \& Lindberg, L.D 2006. "Contraceptive use and pregnancy risk among U.S. high school students, 1991-200." Perspectives on Sexual and Reproductive Health 38, (2): I06-III.

Sen, A 1999. Development as freedom. New York:

Shisana, O., Rice, K., Zungu, N \& Zuma, K 2010. "Gender and poverty in South Africa in the era of HIV/AIDS: a quantitative study". Journal of Women's Health 19, (I):39-46. doi: 10.1089/jwh.2008.1200.

United Nations 2012. The Millennium Development Goals Report. New York, USA: United Nations.

UNDP 2002. Conceptual shifts for sound planning: towards an integrated approach to HIV/AIDS and poverty. Pretoria: UNDP.

UNESCO 2011. Education for all global Monitoring Report 201 I: The hidden crisis, armed conflict and education. UNESCO.

Willan, S 2013. A review of teenage pregnancy in South Africa: Experiences of schooling, and knowledge and access to sexual and reproductive health services. Partners in Sexual Health.

Wright, G \& Noble, M 20I2. Spatial inequality: persistent patterns of child deprivation. In K, Hall., I, Woolard, L, Lake \& Smith, C (eds). South African Child Gauge. Children's Institute, University of Cape, pp. 38-42.

\section{Authors Contributions}

Mhele Karabo conceptualized the research topic, collected and analysed the data. Natal Ayiga participated in the interpretation and discussion of results and final write up of the paper. 